\title{
Mechanics and Human Locomotion
}

Mechanics of Normal and Pathological Locomotion in Man

By Prof. Arthur Steindler. Pp. xix +424 . (London : Baillière, Tindall and Cox, 1935.) 36s. net.

\section{$\mathrm{T}^{\mathrm{T}}$} HIS book by the professor of orthopædic surgery in the University of Iowa is a praiseworthy effort to bring together the recent contributions to the physiology of locomotion and the newer practice of orthopædics on the basis of the general laws of mechanics as applied to human locomotion. The first half of the book deals with the general mechanics of locomotion with special reference to the structure of bone, the centre of gravity of the body, muscle action and fatigue. The second half deals with the special mechanics of locomotion and with 'pathomechanics'. The spine, posture, respiration and the individual joints of the limbs are studied in detail, both in the normal and the abnormal. The final chapters deal with the human gait in walking, running, jumping and climbing. The abnormal gaits of the infirm and crippled are analysed with special reference to the possibility of increasing their physiological efficiency.

The book is a mine of information, but like so many other books in the realm of medicine, it savours strongly of the card index system. There is no attempt to trace a direct path through the maze of theories, hypotheses and laws propounded by anatomists and surgeons who suffered from the static point of view, as distinct from the dynamic point of view of an experimenter such as John Hunter. The book is thus overloaded with tables, statistics and mathematics of doubtful value to such an extent that the reader is apt to be alarmed. Stripped of these, the book still presents a mass of information which could be shaped into a more purposive and more effective essay on locomotion. The illustrations are mainly culled from "Anatomie des Menschen" by Braus; the mechanical drawings are largely original; the legends are often disturbing, for example, cruro varum for crus varum, or gravital for gravitational. Although the author justifiably makes an appeal for more interest and less criticism, yet the reader has a right to expect some measure of style and some historical perspective. The distinguished regius professor of physiology in Glasgow is referred to as one of the "more recent American contributors"; Robert Gasser is rechristened "Gasserer"; John Hunter, Hugh Owen Thomas, Robert Jones in Great Britain, and Whitman of Harvard are not mentioned.

Pruned and trimmed, this book should take a prominent place in the literature of kinesiology and orthopædic surgery.

\section{Plant Study and its Cultural Value}

\section{Intermediate Botany}

By L. J. F. Brimble. Pp. viii +562. (London : Macmillan and Co., Ltd., 1936.) 8s. $6 d$.

THE task which the author has set himself I in planning the book under review has not been an easy one. The exigencies of the examinations for which it is meant to serve as a text-book require the adherence to certain specified aspects of botany, which may be taken to constitute an introductory study of this science. Some textbooks limit themselves to these essentials, and aim at giving a compendium, which can be used with the least trouble, but often with little educational profit, by the student in preparing himself for a definite examination.

The successful teacher should and does clothe these bare bones of a syllabus with an attractive covering of related facts, and endeavours to present the science of botany as a living whole. In that way he not only stimulates those who are entering upon a prolonged study of the subject, but also creates an interest in the minds of those who need to obtain a knowledge of botany as a preliminary requirement before proceeding to medicine, pharmacy or some other science. Text-books rarely attempt this fuller and more really educa. tional treatment of the subject, but this Mr. Brimble has set out to do and he has achieved success.

At the outset, the author emphasises the scope of botany as one of the biological sciences and discusses the characteristics of both groups of living organisms-plants and animals-and their 